\title{
Acoustic Absorption of Natural Fiber Composites
}

\author{
Hasina Mamtaz, Mohammad Hosseini Fouladi, \\ Mushtak Al-Atabi, and Satesh Narayana Namasivayam
}

School of Engineering, Taylor's University, 47500 Subang Jaya, Selangor, Malaysia

Correspondence should be addressed to Hasina Mamtaz; hasina_ctg@yahoo.com

Received 27 November 2015; Revised 21 February 2016; Accepted 17 April 2016

Academic Editor: Mariatti bt Jaafar

Copyright (C) 2016 Hasina Mamtaz et al. This is an open access article distributed under the Creative Commons Attribution License, which permits unrestricted use, distribution, and reproduction in any medium, provided the original work is properly cited.

\begin{abstract}
The current study is a bibliographic observation on prevailing tendencies in the development of acoustic absorption by natural fiber composites. Despite having less detrimental environmental effects and thorough availability, natural fibers are still unsuitable for wide implementation in industrial purposes. Some shortcomings such as the presence of moisture contents, thicker diameter, and lower antifungus quality hold up the progress of natural fiber composites in staying competitive with synthetic composites. The review indicates the importance of the pretreatment of fresh natural fiber to overcome these shortcomings. However, the pretreatment of natural fiber causes the removal of moisture contents which results in the decrease of its acoustic absorption performance. Incorporation of granular materials in treated fiber composite is expected to play a significant role as a replacement for moisture contents. This review aims to investigate the acoustic absorption behavior of natural fiber composites due to the incorporation of granular materials. It is intended that this review will provide an overview of the analytical approaches for the modeling of acoustic wave propagation through the natural fiber composites. The possible influential factors of fibers and grains were described in this study for the enhancement of low frequency acoustic absorption of the composites.
\end{abstract}

\section{Introduction}

The advancement of controlling noise by sound absorption offers a great opportunity to study the acoustic attenuation technique of various porous materials. The available commercial sound absorptive materials used in outdoor and indoor applications can be classified as granular, cellular, and fibrous. Fibrous materials can be either natural or synthetic. The acoustic panels made from natural fibers are less hazardous to human health and more eco-friendly than those made of conventional synthetic fibers [1]. Therefore, growing concern for human health and safety issues has encouraged manufacturers and engineers to seek alternative materials from natural fibers as a replacement for synthetic fibers.

In recent years, researchers like [2-4] started working on the fabrication of fiber composites with the combination of plastic and rubber based granular materials. The incorporation of granular materials such as rubber crumb increases the bulk density and flow resistivity of the composite material, which has a significant effect in enhancing low frequency acoustic absorption. In addition, chemical concentration, fiber-grain composition ratio, fiber size, and grain size may also be vital factors for improving low frequency sound absorption. The combination of natural or conventional fiber and rubber granular materials exhibits an encouraging sound absorption performance at low frequency region when compared with either pure natural fiber or granular composites. But from the point of environmental impact and health hazard issues, these nonrecyclable conventional absorptive materials do not only cause environmental pollution but also contribute to global warming by emitting $\mathrm{CO}_{2}$ gas.

To eliminate these problems, a few researchers like [58] directed their attention in finding sustainable eco-friendly composites with the combination of natural fiber and rubber granular materials or conventional fiber and biogranular materials, which can be named as fibrogranular composites. An encouraging performance of these fibrogranular composites was observed in the evaluation of many indoor and outdoor applications. 
TABLE 1: Advantages and disadvantages of natural fibers $[17,18]$.

\begin{tabular}{ll}
\hline Advantages & Disadvantages \\
\hline $\begin{array}{l}\text { Are biodegradable, cheaper, and eco-friendly and have low specific } \\
\text { weight. }\end{array}$ & $\begin{array}{l}\text { Have lower antifungus, durability, moisture, and fire resistant } \\
\text { qualities. }\end{array}$ \\
$\begin{array}{l}\text { Are abundantly available and high electrical resistant. } \\
\text { Have a negative impact on climate change }\left(\mathrm{CO}_{2} \text { absorption }\right) .\end{array}$ \\
$\begin{array}{l}\text { Have good thermal and acoustic insulating properties. } \\
\text { Have low toxicity and less human health hazards during processing } \\
\text { and handling. }\end{array}$ & $\begin{array}{l}\text { Have to a larger diameter. } \\
\text { causes increase in volume for swelling of the fibers. }\end{array}$ \\
\hline
\end{tabular}

A handful of researchers have focused on natural fiber composites with the combination of natural fiber and granular materials. The objective of this review is to present research development in the area of sound absorption of natural fiber composites combined with granular materials. The aim of the review is to observe the expansion of this field from conventional fibrogranular composites to natural fibrogranular composites for acoustic absorption purposes. The effective physical parameters for enhancing the low frequency absorption in the materials are also highlighted in this review. In addition, three well-known models were demonstrated for evaluating the acoustic parameters of fibrogranular composites.

\section{Natural Fiber Composites}

Due to their biodegradable, lightweight, cheaper, nontoxic, and nonabrasive qualities, natural fibers are receiving much attention in composites as a substitute for synthetic fibers for acoustic absorption purposes. The natural fibers with desirable physical and mechanical properties are exhibited as high performance composites with environmental and economic advantages [15]. Many potential candidates are available in the form of natural fibers for use as sustainable acoustic absorbers. The fibers of coir, corn, paddy, sisal, and banana are some examples. Fiberglass, mineral wool, and glass wool are examples of synthetic fibers. The acoustic performance of synthetic sound absorptive materials is higher than that of natural sound absorptive materials because of their thinner diameter and antifungus quality, but they have a higher environmental impact than the natural fibers [16].

In recent years, natural fiber reinforced resin/polymer composites have earned a lot of attention due to their lightweight, abundant, cost efficient, biodegradable, and ecofriendly nature. Moreover, these materials are cheaper and environmentally superior to glass fiber reinforced composites [26]. However, due to low interfacial adhesion, poor moisture resistance, and the low antifungus quality of natural fiber composites, these materials are still not quite as popular as synthetic based composites.

Researchers are trying to improve the quality of natural fibers through chemical treatment prior to composite production to overcome these shortcomings. It was reported that mercerization or alkaline treatment reduces the fiber diameter and upgrades the quality by improving its adhesive and antifungus quality [17]. The reduction of fiber diameter enhances low frequency sound absorption by providing a more tortuous path and higher surface area, which in turn increases the air flow resistivity of fibrous material. The increase of air flow resistivity causes loss of sound energy through friction of sound waves with air molecules and thus improves low frequency sound absorption [9].

The study analyzes the limitations of natural fibers to achieve their acoustic absorption performance at a desired level. Some of the advantages and disadvantages of natural fibers are furnished in Table $1[17,18]$.

\section{Pretreatment of Natural Fiber}

To achieve fiber fitness, fiber quality, fiber strength, and a better fiber-matrix adhesion in the composite, pretreatment of natural fiber is needed for commercial use in parallel with synthetic fiber. There are various pretreatment techniques available to tune the fiber according to the research requirements. Examples include mercerization or alkaline treatment, graft copolymerization, and plasma treatment. Among them, alkaline treatment or mercerization serves the purpose of this research, as this process reduces the fiber diameter. It is a common method of producing high quality fibers. Mercerization increases the surface roughness of fiber by removing some important substances like lignin, pectin, and hemicelluloses of the fiber. Although the removal of these substances lowers the acoustic absorption performance of the material, it allows better fiber-binder interface adhesion, fiber fitness, longevity, and antifungus quality and most importantly reduces the diameter of the fibers [11, 17, 27].

Figures 1, 2, and 3 demonstrate the inner structure of coir fiber and the appearance of coir fiber before and after alkaline treatment, respectively. It is evident from these three images that alkaline treatment causes a reduction in fiber diameter with the removal of moisture contents.

Figure 3 shows the reduction in fiber diameter due to the alkaline treatment at the cost of the removal of moisture contents. Figure 4 shows that the increase in chemical concentration results in the decrease of fiber diameter and fiber strength as well. It was reported that $6 \%$ of alkali treated coir fiber-epoxy resin composite showed a satisfactory fiber diameter reduction with better mechanical strength compared to untreated composites [11]. 


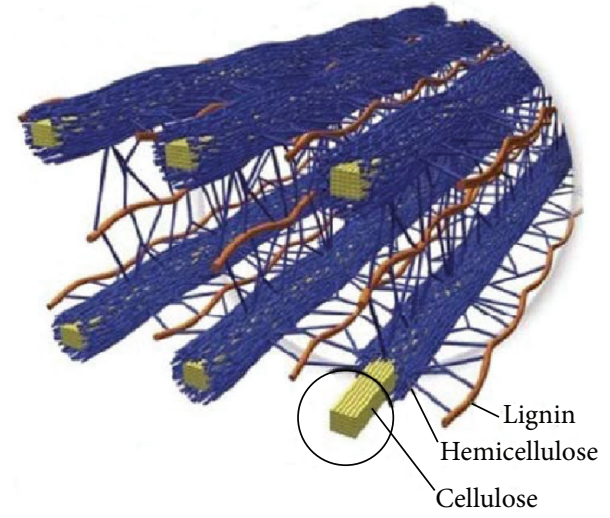

FIGURE 1: The inner structure of coir fiber [9].

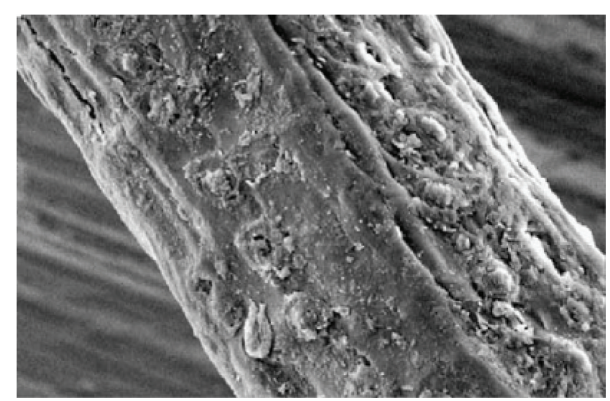

FIGURE 2: The image of fiber structure before alkaline treatment [10].

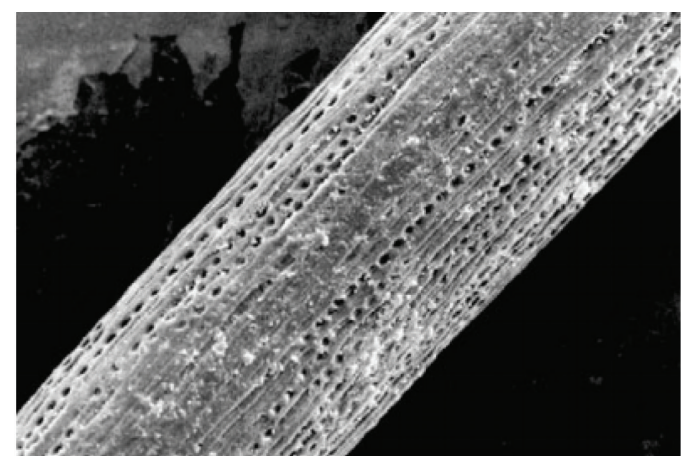

Figure 3: The image of coir fiber structure after alkaline treatment [10].

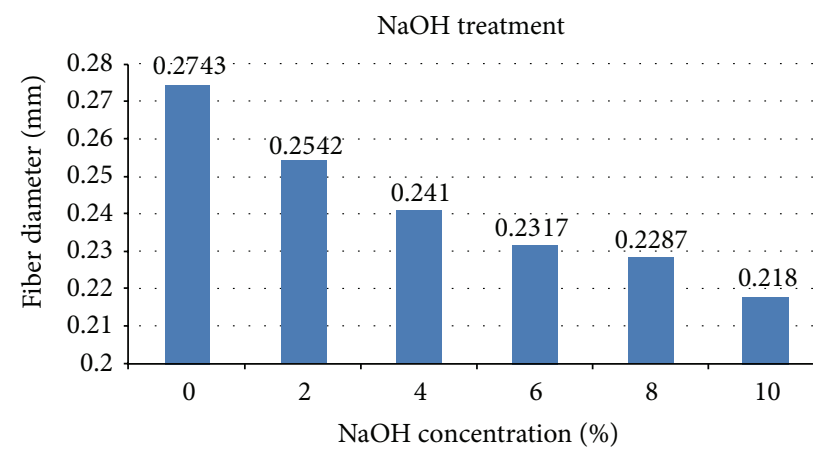

FIgURE 4: Effect of $\mathrm{NaOH}$ concentration on fiber diameter [11].

\section{Fibrogranular Composites}

Fibrous materials are usually composed of groups of orifices formed by interfiber voids and within-fiber voids. The sound absorption of fibrous materials is controlled by these inner and within-fiber voids. Two common kinds of fibrous materials are natural and synthetic. The granular materials are widely accepted as porous sound absorptive material for their sustainability, longevity, and noncombustible and moisture resistant qualities. The granular materials contain pores in their grains where the sound absorption takes place due to viscosity. Usually, there are two kinds of granular materials, consolidated and unconsolidated or loose granular materials. In consolidated granular materials, the particles are relatively rigid and macroscopic and their dimensions are greater than those of the internal voids by many orders of magnitude. Unconsolidated materials are assemblages of loosely packed individual particles. The example of some granular absorbing materials are granular clays, sands, gravel, limestone chips, and soil, which are perfect for controlling outdoor sound propagation $[1,28,29]$.

Fibrogranular composites are the incorporation of granulates made of natural, rubber, or plastic materials into a fibrous matrix. The performance of the fibrogranular composite is the summation of the individual components in which there is a more favorable balance between intrinsic advantages and disadvantages. In a fibrogranular composite, the advantage of one component supplements the lacking of the other to get a resultant balanced performance. Furthermore, in a fibrogranular composite, each component helps in optimizing the acoustic properties of the other material in order to absorb the sound at the desired frequency, so as to yield the highest overall sound absorption. Swift et al. [13] reported that in a rubber granular composite the binder fills the small pores and forms bridges between the grains. This reduces overall porosity and increases the tortuosity and flow resistivity of the material. The investigation confirmed the considerable effect of the binder in predicting the acoustic properties of the granular composite.

A fibrogranular composite is usually a high resistive material with low permeability. This phenomenon causes the material to acquire higher flow resistivity, resulting in higher acoustic absorption at low frequency region. However, low permeability can be a useful factor for the enhancement of low frequency acoustic absorption but it should be within a limit which will allow the material to go through the composite. Otherwise, the compactness of the material may cause the reflection instead of the absorption of the sound waves. A numerical simulation was reported by Berbiche et al. [30], in order to reconstruct the permeability by solving the inverse problem using waves reflected by some high resistive plastic foam samples at different frequency bandwidths in the Darcy regime. Their method is considered as simple compared to the conventional method, as it is independent of frequency and porosity.

Generally, natural fibers need to be mixed with additives to improve their characteristics for commercial acoustic absorption uses. Some natural fibers such as kenaf, hemp, coir, corn, date palm, sugar cane, and jute composites are 
TABLE 2: Acoustic performances of various fibrogranular composites.

\begin{tabular}{|c|c|c|c|c|}
\hline Year & Components & Frequency $(\mathrm{Hz})$ & SAC & Ref. \\
\hline 2008 & Nylon 66 fibers + PVC & 1000 & 0.85 & [19] \\
\hline 2008 & Nylon fibers + RG & 1000 & 0.91 & [19] \\
\hline 2010 & Coconut coir fiber $+\mathrm{RG}$ & 1600 & 0.9 & {$[5]$} \\
\hline 2011 & PVC + Nylon fiber & 1000 & $0.7-1.0$ & [20] \\
\hline 2012 & Pine sawdust $+\mathrm{RG}+\mathrm{PU}$ & 1000 & 0.85 & {$[21]$} \\
\hline 2012 & Ground tire rubber + fiber & $1000-2000$ & $0.8-1.0$ & {$[3]$} \\
\hline 2013 & RG + fiber + RG (multilayer panels) & $1000-1500$ & $5.5-6.5$ & [22] \\
\hline 2013 & Cotton fiber + RG & 500 & 0.74 & [23] \\
\hline
\end{tabular}

SAC, RG, and PU are the sound absorption coefficient, rubber grain, and polyurethane, respectively.

TABLE 3: Influence of porous layer thickness on low frequency acoustic absorption of various fibrous and granular materials.

\begin{tabular}{|c|c|c|c|c|c|}
\hline \multirow[t]{3}{*}{ Materials } & \multicolumn{5}{|c|}{ SAC at $f=500 \mathrm{~Hz}$} \\
\hline & \multicolumn{5}{|c|}{ Thickness } \\
\hline & $10 \mathrm{~mm}$ & $20 \mathrm{~mm}$ & $30 \mathrm{~mm}$ & $40 \mathrm{~mm}$ & $50 \mathrm{~mm}$ \\
\hline Polypropylene & 0.061 & 0.072 & 0.080 & 0.135 & 0.199 \\
\hline Gravelite & 0.066 & 0.079 & 0.101 & 0.138 & 0.185 \\
\hline Rubber & 0.089 & 0.116 & 0.220 & 0.395 & 0.586 \\
\hline Mineral wool & 0.089 & 0.187 & 0.401 & 0.702 & 0.786 \\
\hline High-silica sand & 0.115 & 0.181 & 0.319 & 0.356 & 0.418 \\
\hline
\end{tabular}

made with resin coated fiber, particulate particle strands, veneers, and rubber granular materials. These natural fiber composites have good sound absorption properties by themselves. The effective sound absorption of any composite material can be achieved when it has a more tortuous path, higher surface area, higher flow resistivity, and low porosity within it at the optimal range [31]. A general rule of thumb states that the free spaces within and between fibers can be significantly diminished by the incorporation of any granular materials to achieve effective sound absorption performance. The chronological details on the sound absorption coefficient of some fibrogranular composites are furnished in Table 2.

The information illustrated in Table 3 opens scenarios of possible applications of natural fiber composite with the combination of biogranulates as new sound absorbing materials and points to areas of research for further improvement of their sound absorption performance in the low frequency range.

\section{Theoretical Considerations}

5.1. Delany-Bazley Model. The Delany-Bazley [32] model is a simple and fast approximation technique for the estimation of acoustic parameters of a layer of isotropic and homogenous porous material. The acoustic parameters such as characteristic impedance $\left(Z_{c}\right)$, the propagation constant $(k)$, and surface acoustic impedance $(Z)$ can be obtained as $[33,34]$

$$
\begin{aligned}
Z_{c} & =\rho_{0} c_{0}\left[1+0.057 b^{-0.754}-i\left(0.087 b^{-0.732}\right)\right], \\
k & =\frac{2 \pi f}{c_{0}}\left[0.189 b^{-0.595}+i\left(1+0.0978 b^{-0.7}\right)\right] .
\end{aligned}
$$

Having surface acoustic impedance $(Z)$, the sound absorption coefficient $(\alpha)$ at a normal incidence of the porous layer while backed with a rigid wall can be calculated as

$$
Z=Z_{c} \operatorname{coth}(k \cdot d)
$$

where $\rho_{0}$ is air density; $c_{0}$ is speed of sound in air; $f$ is sound wave frequency; $d$ is thickness of porous layer; $b=\rho_{0} f / \sigma$ which is dimensionless parameter; the model is applicable only for $0.01 \leq b \leq 1.0$.

The technique depends on only one intrinsic property of the material, which is flow resistivity to a certain range of 1000 $\leq \sigma \leq 50000 \mathrm{~N} \cdot \mathrm{s} \mathrm{m}^{-4}$ and porosity close to 1 .

5.2. Johnson-Champoux-Allard Model. Johnson-ChampouxAllard model is a rigid frame model, where the solid phase of the frame remains motionless. Five nonacoustical parameters, flow resistivity, porosity, tortuosity, viscous characteristics length, and thermal characteristics length, are involved in this model. Later two parameters relate the viscous and thermal losses, respectively.

Including the effects of viscosity, the frame geometry dependent parameter viscous characteristic length $(\Lambda)$ was defined by Johnson et al. [35] as follows:

$$
\Lambda=2 \frac{\int v_{\text {fluid }}^{2} d A}{\int v_{\text {fluid }}^{2} d V} .
$$


In (17), the numerator denotes the velocity of fluid over the pores surface area $A$ and the denominator denotes the velocity inside the pores volume $V$.

The relation between the viscous characteristic length and flow resistivity $(\sigma)$ was noted by Johnson et al. [35] as follows:

$$
\Lambda=\frac{1}{c}\left(\sqrt{\frac{8 \eta \alpha_{\infty}}{\sigma \phi}}\right)
$$

where $c$ is a constant and is close to 1 .

The expression of the effective density $\rho(\omega)$ of rigid framed porous materials, which was proposed by Johnson et al. [36], is stated in

$$
\rho(\omega)=\alpha_{\infty} \rho_{0}\left[1+\frac{\sigma \phi}{j \omega \rho_{0} \alpha_{\infty}} \sqrt{1+\frac{4 \alpha_{\infty}^{2} \eta \rho_{0} \omega}{\sigma^{2} \Lambda^{2} \omega^{2}}}\right]
$$

According to Champoux and Allard [37], the thermal characteristic length $\left(\Lambda^{\prime}\right)$, which characterizes the high frequency behavior of the bulk modulus $K(\omega)$, is given by

$$
\Lambda^{\prime}=2 \frac{\int d A}{\int d V}=2 \frac{A}{V}
$$

where $A$ and $V$ are the surface area of and volume of the pores, respectively.

In the case of fibrous materials with porosity close to $1, \Lambda$ and $\Lambda^{\prime}$ can be stated as in (7) and (8), respectively [38]:

$$
\begin{aligned}
\Lambda & =\frac{1}{2 \pi r l}, \\
\Lambda^{\prime} & =\frac{1}{\pi r l}=2 \Lambda, \\
l & =\frac{1}{\pi r^{2} * \rho_{\text {bulk }} / \rho_{\text {fiber }}},
\end{aligned}
$$

where $l$ is total length of fiber per unit volume; $r$ is crosssectional radius of fiber; $\rho_{\text {bulk }}$ is bulk density of porous material; $\rho_{\text {fiber }}$ is density of fiber; $\rho_{\text {bulk }} / \rho_{\text {fiber }}$ is fraction of fiber existing in porous material.

The expression of the bulk modulus $K(\omega)$ of rigid framed porous materials, which was proposed by Champoux and Allard [37, 38], is stated in

$$
K(\omega)=\frac{\gamma P_{0}}{\gamma-(\gamma-1)\left[1-j\left(8 \eta / \Lambda^{\prime 2} N_{p} \rho_{0} \omega\right) \sqrt{1+j\left(\Lambda^{\prime 2} N_{p} \rho_{0} \omega / 16 k\right)}\right]^{-1}},
$$

where $\eta$ is viscosity of air; $\Lambda^{\prime}$ is thermal characteristic length; $\omega$ is angular frequency; $\gamma$ is ratio of specific heat at constant pressure to specific heat at constant volume; $P_{0}$ is atmospheric pressure; $N_{p}$ is Prandtl number; $\rho_{0}$ is density of air.

The expression for characteristic impedance $Z_{c}(\omega)$, the complex wave number $k_{c}(\omega)$, and surface acoustic impedance $Z$ can be estimated by the following equations [38, 39]:

$$
\begin{aligned}
Z_{c}(\omega) & =\frac{1}{\phi} \sqrt{\rho(\omega) \cdot K(\omega)}, \\
k_{c}(\omega) & =\omega \sqrt{\frac{\rho(\omega)}{K(\omega)}}, \\
Z & =Z_{c}(\omega) \cdot \operatorname{coth}\left(k_{c}(\omega)\right) .
\end{aligned}
$$

5.3. Biot-Allard Model. Allard's model [40], in addition to his extension to Biot [41], is an elastic frame method for the porous material which is saturated with viscous fluid. In this model the frame (fiber) is assumed as elastic cylindrical fiber, which deals with the study of the frame-fluid interaction. Hence, both frame (fiber) and fluid (air) are in motion.

The frequency dependent bulk modulus of fluid, $K_{f}(\omega)$ inside the pore, which is assumed to be the only parameter to characterize the air filling pores, is defined as [40]

$$
K_{f}(\omega)=\frac{\gamma P_{0}}{\gamma-(\gamma-1)\left[1+\left(8 \eta / j \Lambda^{\prime 2} N_{p} \omega \rho_{0}\right)\left(1+j \rho_{0}\left(\omega N_{p} \Lambda^{\prime 2} / 16 \eta\right)\right)^{1 / 2}\right]^{-1}}
$$


Allard [40] derived the elasticity coefficients $P, Q$, and $R$ in terms of Biot's experiments as follows:

$$
\begin{aligned}
P & ={ }_{3}^{4} N+K_{b}+\frac{(1-\varphi)^{2}}{\varphi} K_{f}, \\
Q & =K_{f}(1-\varphi), \\
R & =K_{f} \varphi .
\end{aligned}
$$

The bulk modulus of frame $K_{b}$ can be evaluated as

$$
K_{b}=\frac{2 N(\nu+1)}{3(1-2 \nu)}
$$

where $N$ is shear modulus; $v$ is Poisson coefficient.

The dynamic rigidity of the elastic solid was characterized by the shear modulus and Poisson coefficient. The derivation of the kinetic energy helps in the evaluation of the equation of motion in an elastic medium. The parameters $\rho_{11}^{*}, \rho_{12}^{*}$, and $\rho_{22}^{*}$, which help to identify the inertial coupling between frame and fluid, can be estimated as [40]

$$
\begin{gathered}
\rho_{11}^{*}=\rho_{\text {bulk }}+\rho_{a}-j \sigma \varphi^{2} \frac{G(\omega)}{\omega}, \\
\rho_{12}^{*}=-\rho_{a}+j \sigma \varphi^{2} \frac{G(\omega)}{\omega}, \\
\rho_{22}^{*}=\varphi \rho_{0}+\rho_{a}-j \sigma \varphi^{2} \frac{G(\omega)}{\omega},
\end{gathered}
$$

where

$$
\begin{aligned}
G_{\omega} & =\left(1+\frac{4 j \alpha_{\infty}^{2} \eta \rho_{0} \omega}{\sigma^{2} \Lambda^{2} \varphi^{2}}\right)^{1 / 2}, \\
\rho_{a} & =\rho_{0} \varphi\left(\alpha_{\infty}-1\right)=\text { Inertial coupling term. }
\end{aligned}
$$

$\alpha_{\infty}$ is the tortuosity of the frame, which is defined as [42]

$$
\alpha_{\infty} \approx \frac{1}{\sqrt{\varphi}} .
$$

According to Biot [41], there are two compression waves and one shear wave which propagate in porous media. One compression wave is air borne, which mostly transmits in air, and another one is frame borne, which propagates in both of them. A rotational wave called shear wave is also frame borne, which is considered when the sound waves propagate at oblique incidence. The study only analyzes the propagation of sound at normal incidence, and hence only two compression waves are considered here.

To calculate the ratio of frame and fluid velocity, the squared wave numbers of two compression waves can be evaluated as

$$
\begin{aligned}
& \delta_{1}^{2}=\frac{\omega^{2}}{2\left(P R-Q^{2}\right)}\left[P \rho_{22}^{*}+R \rho_{11}^{*}-2 Q \rho_{12}^{*}-\sqrt{\Delta}\right], \\
& \delta_{2}^{2}=\frac{\omega^{2}}{2\left(P R-Q^{2}\right)}\left[P \rho_{22}^{*}+R \rho_{11}^{*}-2 Q \rho_{12}^{*}+\sqrt{\Delta}\right],
\end{aligned}
$$

where

$$
\begin{aligned}
\Delta= & \left(P \rho_{22}^{*}+R \rho_{11}^{*}+2 Q \rho_{12}^{*}\right)^{2} \\
& -4\left(P R-Q^{2}\right)\left(\rho_{11}^{*} \rho_{22}^{*}-\rho_{12}^{* 2}\right) .
\end{aligned}
$$

The squared wave numbers are useful to calculate the ratio of frame and fluid velocity:

$$
\mu_{i}=\frac{P \delta_{i}^{2}-\omega^{2} \rho_{11}^{*}}{\omega^{2} \rho_{12}^{*}-Q \delta_{i}^{2}} .
$$

As two compression waves simultaneously propagate in both media, four characteristic impedances related to the propagation in air $Z_{i}^{a}$ or frame $Z_{i}^{f}$ can be evaluated as

$$
\begin{aligned}
& Z_{i}^{a}=\left(R+\frac{Q}{\mu_{i}}\right) \frac{\delta_{i}}{\varphi \omega}, \\
& Z_{i}^{f}=\left(P+Q \mu_{i}\right) \frac{\delta_{i}}{\omega},
\end{aligned}
$$

where $i=1,2$ in the case of (20) and (21).

The surface acoustic impedance at normal incidence $(Z)$ of the material with thickness $d$, which is the function of the above characteristic impedances, can be calculated as

$$
Z=-j \frac{\left(Z_{1}^{f} Z_{2}^{a} \mu_{2}-Z_{2}^{f} Z_{1}^{a} \mu_{1}\right)}{D},
$$

where

$$
\begin{aligned}
D= & \left(1-\varphi+\varphi \mu_{2}\right)\left[Z_{i}^{f}-(1-\varphi) Z_{i}^{a} \mu_{1}\right] \operatorname{tg} \delta_{2} d \\
& +\left(1-\varphi+\varphi \mu_{1}\right)\left[Z_{2}^{a} \mu_{2}(1-\varphi)-Z_{2}^{f}\right] \operatorname{tg} \delta_{1} d .
\end{aligned}
$$

Hence, the sound propagation in elastic materials is modeled by implementing the above-mentioned formulation.

Having the surface acoustic impedance $(Z)$, the absorption coefficient $(\alpha)$ at a normal incidence of the porous layer while backed with a rigid wall can be calculated as

$$
\alpha=1-\left|\frac{Z-Z_{0}}{Z+Z_{0}}\right|^{2},
$$

where $Z_{0}=\rho_{0} \mathcal{c}_{0}$ which is impedance of the air.

The effectiveness of any porous material depends on the value of its sound absorption coefficient which is close to one, with an absorption plane on a large frequency range.

\section{Effective Factors for Low Frequency Acoustic Absorption}

6.1. Fiber Size. Fiber diameter is the most important physical geometrical parameter for enhancing the sound absorption performance of any fibrous material. The decrease in fiber diameter leads to an increase in the value of the sound absorption coefficient. This is because more fibers are required to reach the same volume density at the same thickness of the sample material. This results in a more tortuous path 
and higher airflow resistance. As a result, the acoustical performance of the sample material increases due to the viscous friction through air vibration [31].

The accession of thinner fibers due to the reduction of fiber diameter results in a high specific surface area and more micropores in equal volume density of the sample material. This increases the value of the sound absorption coefficient due to more friction of air molecules with a larger surface area [43]. Furthermore, thin fiber moves more easily than thick fiber in sound waves, which causes vibration in the air, and this enhances absorption by means of more viscous losses due to air vibration [44].

These observations indeed help us to show that fiber diameter is an important parameter in enhancing the sound absorption in the low frequency region. The significant enhancement in low frequency absorption was found due to the reduction of coir fiber diameter in the numerical simulation of Nor et al. [9] for the range of fiber sizes from 100 to $250 \mu \mathrm{m}$ at $50 \mathrm{~mm}$ constant thickness of the sample material. The study reported the gradual increase and shift of the peak of the sound absorption coefficient with the decrease of fiber diameter towards the low frequency region.

A strong influence of fiber fineness on the sound absorption performance of the nonwoven fabrics was reported by Shahani et al. [12]. They stated that finer fiber with reduced diameter absorbed the sound more efficiently than the thick, coarse fiber. The finer fibers enhance the sound absorption performance of nonwoven fabric material by reducing the possible connectivity of pores. The variation of the sound absorption performance at different fiber diameters is illustrated in Figure 5.

6.2. Grain Size. Voronina and Horoshenkov [45] developed a new empirical model which relates the characteristic impedance and propagation constant with characteristic particle dimension, porosity, tortuosity, and the specific density of grain base. The study reported a reliable prediction of the acoustic performance of a loose granular mix of grain base $0.4-3.5 \mathrm{~mm}$ and specific densities between 200 and $1200 \mathrm{~kg} / \mathrm{m}^{3}$, in the frequency range $250-4000 \mathrm{~Hz}$.

Sakamoto et al. [6] investigated the sound absorbing characteristics of two biogranular materials, rice and buckwheat husks. They revealed the effectiveness of rice husk and buckwheat husk as sound absorbing materials. They found that the value of the sound absorption coefficient of rice husk is 0.5 and buckwheat husk is 4.5 at $500 \mathrm{~Hz}$ and $40 \mathrm{~mm}$ thickness.

Swift et al. [13] reported that the flow resistivity is directly proportional to the internal surface area of the granular composite material, while the internal surface area is inversely proportional to the grain size. They confirmed that unconsolidated granulates of grain sizes between 0.71 and $1 \mathrm{~mm}$ and consolidated material of grain size $<2 \mathrm{~mm}$ contribute higher flow resistivity, on the condition of applying the binder at a suitable ratio. Their report can be explained by the fact that smaller grains show higher flow resistivity than larger grains, leading to higher acoustic absorption performance.

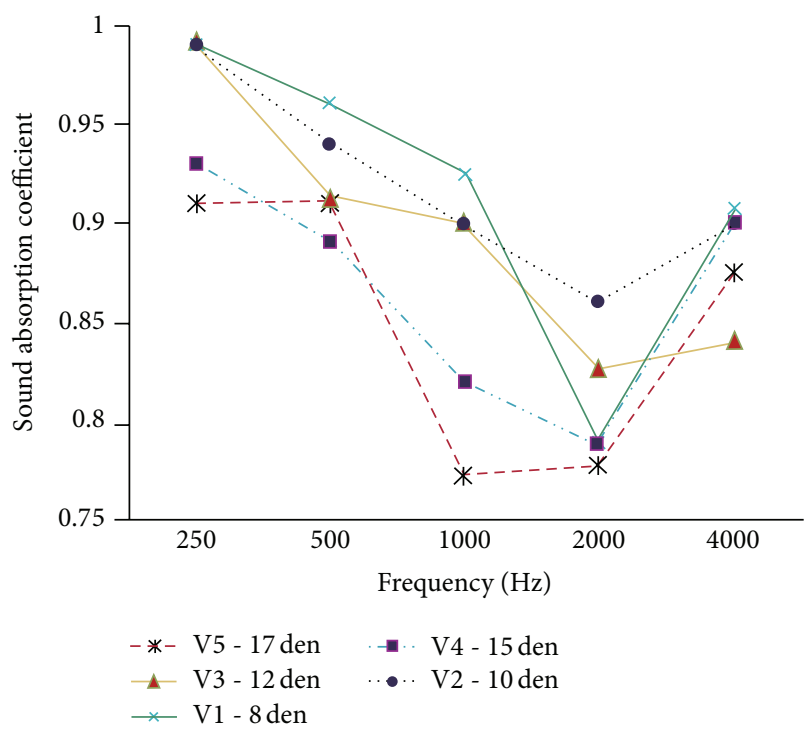

FIGURE 5: Variation of the sound absorption coefficient at different fiber diameters [12].

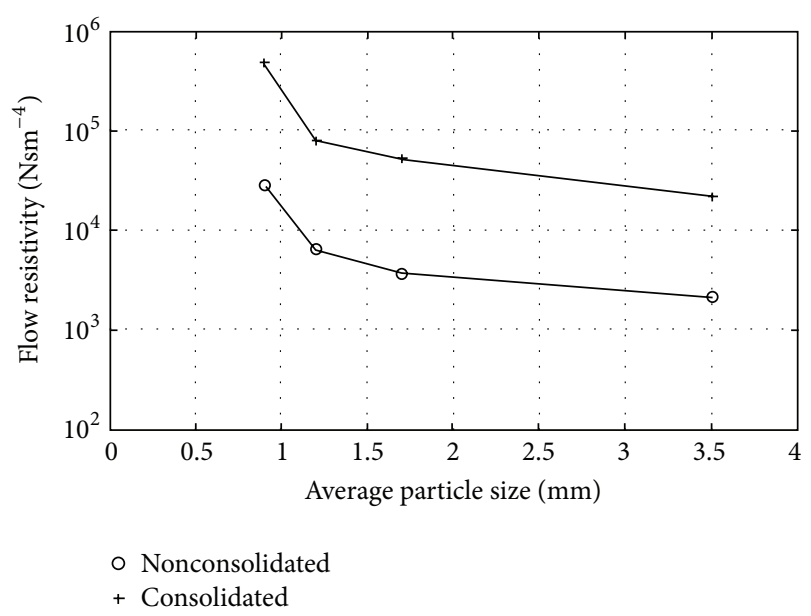

FIGURE 6: Influence of the grain size on the flow resistivity of consolidated and unconsolidated granular materials [13].

A comparison study of flow resistivity of consolidated and unconsolidated grain materials is shown in Figure 6 for each grain size.

Their report can be explained by the fact that smaller grains show higher flow resistivity than the larger grains, resulting in higher acoustic absorption performance for both grain types.

6.3. Bulk Density. The density of a material is often a significant factor governing its sound absorption qualities. The investigation of materials density is very important, as the current study is dealing with the combined density of two materials such as fibrous and granular material. Koizumi et al. [31] stated that the increase in sample density causes an increase in sound absorption at medium and high frequency regions. They explained that, with increases in the number of 


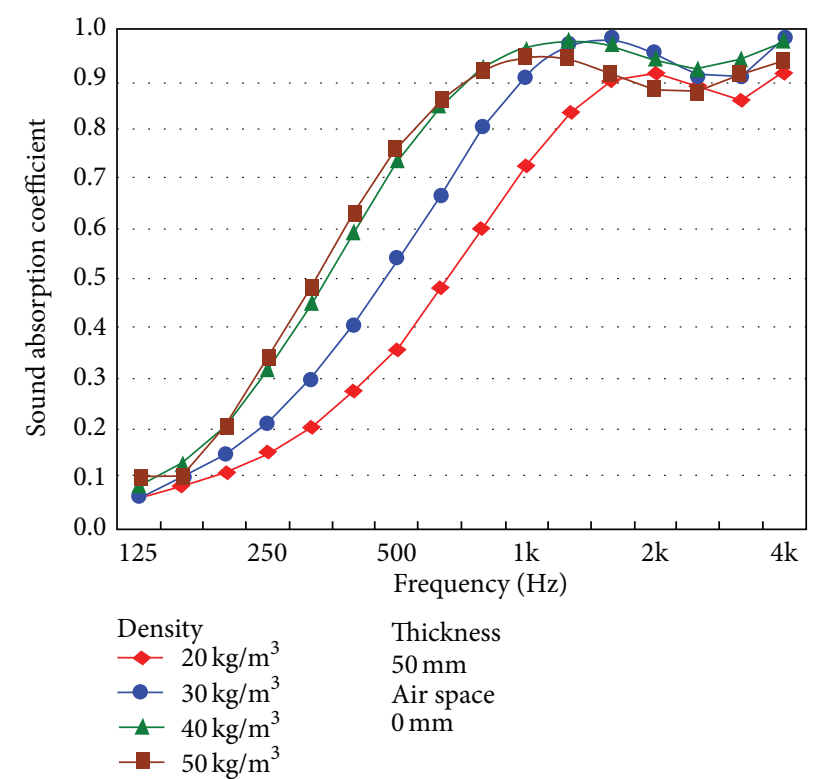

FIgURE 7: Variation of sound absorption coefficients at different bulk densities [14].

fibers per unit area, the sample density increases. As a result, energy loss of sound waves increases due to the increase of surface friction, which leads to an increase in sound absorption performance.

Tiuc et al. [46] reported that the sound absorption coefficient for flexible polyurethane foam with a density of $60 \mathrm{~kg} / \mathrm{m}^{3}$ was higher than glass wool with a density of $15 \mathrm{~kg} / \mathrm{m}^{3}$ at medium and high frequency ranges. The influence of the bulk density was observed in the acoustic performance of bamboo wool materials. The increase in bulk density of the bamboo wool material moved the peak value of the sound absorption coefficient from the high to the low frequency range [14]. Figure 7 presents the variation of the sound absorption coefficient at different bulk densities of bamboo wool material.

6.4. Sample Layer Thickness. According to general guidelines of absorption phenomena inside a porous material, a long dissipative process of viscosity and thermal conduction between the air and absorbing material within the composite improves the absorption. This improved sound absorption is due to the increased thickness of the sample material. Nor et al. [9] demonstrated the significant role of fiber layer thickness on acoustic absorption of fresh and industrial coir fiber. They implemented the Johnson-Allard rigid frame model to estimate the acoustic absorption performance of coir fiber at different thicknesses. They found that for both cases increasing the coir fiber layer thickness increases the absorption and moves the absorption peak towards the low frequency region.

Increasing the sample layer thickness has a significant effect on enhancing the sound absorption at the low frequency region of the porous material, while there is an insignificant effect at the higher frequency range [47].
TABLE 4: List of the sound absorption coefficients of different fibrous material at different frequencies.

\begin{tabular}{lccc}
\hline Materials & Fiber diameter $(\mu \mathrm{m})$ & SAC at $f=500 \mathrm{~Hz}$ & Ref. \\
\hline Cotton & 13.5 & 0.50 & \\
Flax & 21.8 & 0.40 & \\
Ramie & 24.4 & 0.40 & {$[24,25]$} \\
Wool & 37.1 & 0.20 & \\
Jute & 81.2 & 0.20 & \\
Sisal & 213 & 0.10 & \\
\hline
\end{tabular}

The effective absorption of the incident sound wave occurs when the thickness of the material is one-tenth of its wavelength [48]. The influence of layer thickness on the sound absorbing properties of various fibrous and granular materials is furnished in Table 3 at the frequency of $500 \mathrm{~Hz}$ for five-layer thicknesses.

From the information provided in Table 3, it is clearly evident that increasing sample layer thickness of any porous sound absorption material promotes the sound absorption coefficient at the low frequency region.

\section{Results and Discussions}

Based on the investigation of various analytical and experimental overviews, various potential factors were found to enhance the low frequency acoustic absorption. These factors are fiber size, grain size, bulk density, sample layer thickness, and so forth. According to researchers, decreasing fiber diameter resulted in the increase of fiber content in the composite and absorption by means of more viscous friction of air molecules with a larger surface area. Hence, the decrease in fiber diameter causes the dramatic increase in the flow resistivity as well as sound absorption performance of the fiber materials towards low frequency [31, 49]. The variation of the values of sound absorption coefficients with the values of various fiber diameters is furnished in Table 4 .

Investigations carried out by many researchers confirmed the clear relationship between the absorption spectra and the size of the granular particles. Pfretzschner [4] stated that the sound absorption efficiency of rubber granular materials depends on its particles' size and layer thickness. The absorption increases to its maximum with decreases in grain size, and most optimum sound absorption is acquired for rubber grain sizes between 0.5 and $1 \mathrm{~mm}$ [13].

A comparison study was made by Mahzan et al. [50] among rice husk, rubber granulate, and woods shaved materials to validate the effectiveness of rice husk as an acoustic material. Their result demonstrated that the acoustic performance of $25 \%$ rice husk together with a polyurethane binder is superior to rubber and woods shaved material. Table 5 presents the comparison study of sound absorption coefficients for rice husk with rubber and woods shaved materials.

The acoustic absorption performance of a fibrogranular composite was better among simple rubber granulates, cotton 
TABLE 5: A comparison study of the acoustic performance of biogranular and rubber granular materials.

\begin{tabular}{lc}
\hline Materials & SAC \\
\hline Rice husk & 0.9 \\
Rubber grains & 0.583 \\
Woods shaved & 0.484 \\
\hline
\end{tabular}

TABLE 6: Acoustic absorption study of fibrous, granular, and fibrogranular composites [23].

\begin{tabular}{lccc}
\hline Materials & \multicolumn{3}{c}{ SAC at $500 \mathrm{~Hz}$} \\
\hline & $30 \mathrm{~mm}$ & $40 \mathrm{~mm}$ & $50 \mathrm{~mm}$ \\
\hline Cotton fiber-rubber granulate & 0.29 & 0.42 & 0.74 \\
Cotton fiber & 0.34 & 0.37 & 0.62 \\
Rubber granulate & 0.12 & 0.18 & 0.26 \\
\hline
\end{tabular}

fiber, and cotton fiber-rubber granulate composites. A comparison study is furnished in Table 6 for the sound absorption coefficient at frequency $500 \mathrm{~Hz}$ and different layer thicknesses of these three materials [23].

The information provided in Table 3 is also a clear indication of the significant contribution of the increase in sample layer thickness for enhanced acoustic absorption performance of three types of materials.

\section{Conclusion}

Natural fibers have already confirmed their potentiality in replacing common synthetic fibrous materials for acoustic absorption purposes. However, in real world applications, natural fibers should be pretreated to improve their antifungus quality and life expectancy. The study highlighted the possible ways to improve the acoustic behavior of natural fiber composites as high quality absorbers, in combination with biobased granular materials.

The alkaline treatment process causes the reduction of fiber diameter at the cost of the removal of moisture absorbents such as oil, cellulose, and wax of the natural fiber, thus improving adhesion and antifungus qualities of the composite. However, limited research was reported on the effect of the sound absorption performance due to alkaline treatment. More research is needed on the effect of the mercerization or alkaline treatment for acoustic absorption performance.

In fibrogranular composite materials, there is good potential in filling the small pores by the granular component and the formation of bridges between the fibers as well. This contributes a higher surface area within the composite. Materials with higher density show increased absorption performance, since the density has a great influence on the porosity and flow resistivity of the composite.

The acoustic absorption of natural fiber composites can be estimated by using the Delany-Bazley, Biot-Allard, and Johnson-Champoux-Allard analytical models. The DelanyBazley model is the only method that shows the general absorption pattern at overall broadband frequency without giving any information on the peaks and resonance of the frame. The other two models give accurate information about peaks and resonance of the frame.

Reduction in fiber diameter causes an increase in the fiber content and hence a high specific surface area in the composites. Thus, the loss of more energy due to the viscous friction of air molecules with higher surface area increases the value of the sound absorption coefficient at the low frequency region.

Influence of grain size has a considerable effect on the acoustic properties of granular composite materials. For large grains, the absorption is generally low due to low flow resistivity, but for smaller grains the absorption increases due to high flow resistivity and tortuosity. The maximum sound absorption 0.95 was found for rubber grain sizes $0.5-$ $1 \mathrm{~mm}$. Biogranular materials such as rice husk have a better potential for commercialization as low frequency sound absorbent material compared to rubber and wood shavings at its optimum percentage with polyurethane binder.

Sample layer thickness also plays an important role in enhancing low frequency sound absorption. The reason is the increase in layer thickness, causing the incident sound waves to lose more energy as they take a longer path through the material. In thicker materials, the impinged sound waves have to undergo a long dissipative procedure of viscosity and thermal conduction in the air within the composite.

The review rests great hopes in developing the new natural fiber composite material with the use of biobased grains for acoustic absorption purposes. The manufacture of these new materials by combining waste residues will contribute to environmental protection and sustainable acoustic absorption solutions that are cheaper than the traditional alternatives. Extensive investigation is needed for the improvement of lower frequency sound absorption performance, considering the various effective physical parameters of the material.

\section{Competing Interests}

The authors declare that they have no competing interests.

\section{References}

[1] J. P. Arenas and M. J. Crocker, "Recent trends in porous soundabsorbing materials," Sound \& Vibration, vol. 44, no. 7, pp. 12-18, 2010.

[2] R. Maderuelo-Sanz, J. M. Barrigón Morillas, M. MartínCastizo, V. Gómez Escobar, and G. Rey Gozalo, "Acoustical performance of porous absorber made from recycled rubber and polyurethane resin," Latin American Journal of Solids and Structures, vol. 10, no. 3, pp. 585-600, 2013.

[3] R. Maderuelo-Sanz, A. V. Nadal-Gisbert, J. E. Crespo-Amorós, and F. Parres-García, "A novel sound absorber with recycled fibers coming from end of life tires (ELTs)," Applied Acoustics, vol. 73, no. 4, pp. 402-408, 2012.

[4] J. Pfretzschner, Rubber Crumb as Granular Absorptive Acoustic Material, Instituto de Acústica, Madrid, Spain, 2002.

[5] S. Mahzan, A. M. Ahmad Zaidi, N. Arsat, M. N. M. Hatta, M. I. Ghazali, and S. R. Mohideen, "Study on sound absorption 
properties of coconut coir fibre reinforced composite with added recycled rubber," International Journal of Integrated Engineering, vol. 2, no. 1, pp. 29-34, 2010.

[6] S. Sakamoto, Y. Takauchi, K. Yanagimoto, and S. Watanabe, "Study for sound absorbing materials of biomass tubule etc.," Journal of Environment and Engineering, vol. 6, no. 2, pp. 352364, 2011.

[7] A. Borlea, T. Rusu, O. Vasile, and A. Gheorghe, "Sound proofing materials with recycled rubber particles and sawdust," in Proceedings of the 23rd Symposium of the Institute of Solid Mechanics (SISOM '12), pp. 291-296, Bucharest, Romania, May 2012.

[8] B. Ekici, A. Kentli, and H. Küçük, "Improving sound absorption property of polyurethane foams by adding tea-leaf fibers," Archives of Acoustics, vol. 37, no. 4, pp. 515-520, 2012.

[9] M. J. M. Nor, M. Ayub, R. Zulkifli, N. Amin, and M. H. Fouladi, "Effect of different factors on the acoustic absorption of coir fiber," Journal of Applied Sciences, vol. 10, no. 22, pp. 2887-2892, 2010.

[10] H. Gu, "Tensile behaviours of the coir fibre and related composites after $\mathrm{NaOH}$ treatment," Materials \& Design, vol. 30, no. 9, pp. 3931-3934, 2009.

[11] A. Karthikeyan and K. Balamurugan, "Effect of alkali treatment and fiber length on impact behavior of coir fiber reinforced epoxy composites," Journal of Scientific \& Industrial Research, vol. 71, no. 9, pp. 627-631, 2012.

[12] F. Shahani, P. Soltani, and M. Zarrebini, "The analysis of acoustic characteristics and sound absorption coefficient of needle punched nonwoven fabrics," Journal of Engineered Fibers \& Fabrics, vol. 9, no. 2, pp. 84-92, 2014.

[13] M. J. Swift, P. Briš, and K. V. Horoshenkov, "Acoustic absorption in re-cycled rubber granulate," Applied Acoustics, vol. 57, no. 3 , pp. 203-212, 1999.

[14] N. TsujiuchiI, T. Koizumi, Y. Ohshima, and T. Kitagawa, An Optimal Design and Application of Sound-Absorbing Material Made of Exploded Bamboo Fibers, Department of Mechanical Engineering, Doshisha University, Kyoto, Japan, 2002.

[15] M. Avella, G. La Rota, E. Martuscelli et al., "Poly(3hydroxybutyrate-co-3-hydroxyvalerate) and wheat straw fibre composites: thermal, mechanical properties and biodegradation behaviour," Journal of Materials Science, vol. 35, no. 4, pp. 829-836, 2000.

[16] F. Asdrubali, "Green and sustainable materials for noise control in buildings," in Proceedings of the 19th International Congress on Acoustics, Madrid, Spain, 2007.

[17] S. Kalia, B. S. Kaith, and I. Kaur, "Pretreatments of natural fibers and their application as reinforcing material in polymer composites-a review," Polymer Engineering \& Science, vol. 49, no. 7, pp. 1253-1272, 2009.

[18] F. Asdrubali, "Survey on the acoustical properties of new sustainable materials for noise control," in Proceedings of the Euronoise 2006, Tampere, Finland, 2006.

[19] A. Khan, Vibro-acoustic products from re-cycled raw materials using a cold extrusion process: a continuous cold extrusion process has been developed to tailor a porous structure from polymeric waste, so that the final material possesses particular vibro-acoustic properties [Ph.D. thesis], University of Bradford, Bradford, UK, 2008.

[20] H. Benkreira, A. Khan, and K. V. Horoshenkov, "Sustainable acoustic and thermal insulation materials from elastomeric waste residues," Chemical Engineering Science, vol. 66, no. 18, pp. 4157-4171, 2011.
[21] T. Rusu and O. Vasile, "Investigation composite materials for its sound absorption properties," Romanian Journal of Acoustics \& Vibration, vol. 9, no. 2, pp. 123-126, 2012.

[22] E. Juliá, J. Segura, A. Nadal, J. M. Gadea, and J. E. Crespo, "Study of sound absorption properties of multilayer panels made from ground tyre rubbers," Fascicle of Management and Technological Engineering, vol. 1, pp. 147-150, 2013.

[23] J. Turkiewicz and J. Sikora, "Sound absorbing materials from recycled rubber products," Mechanics and Control, vol. 32, no. 3, pp. 117-121, 2013.

[24] D. J. Oldham, C. A. Egan, and R. D. Cookson, "Sustainable acoustic absorbers from the biomass," Applied Acoustics, vol. 72, no. 6, pp. 350-363, 2011.

[25] W. D. Yang and Y. Li, "Sound absorption performance of natural fibers and their composites," Science China Technological Sciences, vol. 55, no. 8, pp. 2278-2283, 2012.

[26] S. V. Joshi, L. T. Drzal, A. K. Mohanty, and S. Arora, "Are natural fiber composites environmentally superior to glass fiber reinforced composites?" Composites Part A: Applied Science and Manufacturing, vol. 35, no. 3, pp. 371-376, 2004.

[27] H. Demir, U. Atikler, D. Balköse, and F. Tihmınlığlu, “The effect of fiber surface treatments on the tensile and water sorption properties of polypropylene-luffa fiber composites," Composites Part A: Applied Science and Manufacturing, vol. 37, no. 3, pp. 447-456, 2006.

[28] J. Sikora and J. Turkiewicz, "Sound absorption coefficients of granular materials," Mechanics and Control, vol. 29, no. 3, pp. 149-157, 2010.

[29] G. Iannace, C. Ianniello, L. Maffei, and R. Romano, "Steady-state air-flow and acoustic measurement of the resistivity of loose granular materials," Journal of the Acoustical Society of America, vol. 106, no. 3, pp. 1416-1419, 1999.

[30] A. Berbiche, M. Sadouki, Z. Fellah et al., "Experimental determination of the viscous flow permeability of porous materials by measuring reflected low frequency acoustic waves," Journal of Applied Physics, vol. 119, no. 1, Article ID 014906, 2016.

[31] T. Koizumi, N. Tsujiuchi, and A. Adachi, "The development of sound absorbing materials using natural bamboo fibers," High Performance Structures and Materials, vol. 4, pp. 157-166, 2002.

[32] M. E. Delany and E. N. Bazley, "Acoustical properties of fibrous absorbent materials," Applied Acoustics, vol. 3, no. 2, pp. 105-116, 1970.

[33] F.-C. Lee and W.-H. Chen, "Acoustic transmission analysis of multi-layer absorbers," Journal of Sound and Vibration, vol. 248, no. 4, pp. 621-634, 2001.

[34] I. P. Dunn and W. A. Davern, "Calculation of acoustic impedance of multi-layer absorbers," Applied Acoustics, vol. 19, no. 5, pp. 321-334, 1986.

[35] D. L. Johnson, J. Koplik, and L. M. Schwartz, "New pore-size parameter characterizing transport in porous media," Physical Review Letters, vol. 57, article 2564, 1986.

[36] D. L. Johnson, J. Koplik, and R. Dashen, "Theory of dynamic permeability and tortuosity in fluid-saturated porous media," Journal of Fluid Mechanics, vol. 176, pp. 379-402, 1987.

[37] Y. Champoux and J.-F. Allard, "Dynamic tortuosity and bulk modulus in air-saturated porous media," Journal of Applied Physics, vol. 70, no. 4, pp. 1975-1979, 1991.

[38] J. F. Allard, Propagation of Sound in Porous Media: Modelling Sound Absorbing Materials, Elsevier Application Science, New York, NY, USA, 1993. 
[39] N. Kino, T. Ueno, Y. Suzuki, and H. Makino, "Investigation of non-acoustical parameters of compressed melamine foam materials," Applied Acoustics, vol. 70, no. 4, pp. 595-604, 2009.

[40] J. Allard, Sound Propagation in Porous Media: Modelling Sound Absorbing Materials, Elsevier, London, UK, 1993.

[41] M. Biot, "Generalized theory of acoustic propagation in porous dissipative media," The Journal of the Acoustical Society of America, vol. 34, no. 9A, pp. 1254-1264, 1962.

[42] K. Attenborough, "Models for the acoustical characteristics of air filled granular materials," Acta Acustica, vol. 1, pp. 213-226, 1993.

[43] R. Asmatulu, W. Khan, and M. B. Yildirim, "Acoustical properties of electrospun nanofibers for aircraft interior noise reduction," in Proceedings of the ASME International Mechanical Engineering Congress and Exposition, American Society of Mechanical Engineers, Lake Buena Vista, Fla, USA, November 2009.

[44] T. J. Cox and P. D’antonio, Acoustic Absorbers and Diffusers: Theory, Design and Application, Taylors \& Francis, New York, NY, USA, 2009.

[45] N. N. Voronina and K. V. Horoshenkov, "A new empirical model for the acoustic properties of loose granular media," Applied Acoustics, vol. 64, no. 4, pp. 415-432, 2003.

[46] A. E. Tiuc, O. Vasile, U. Anamaria-Didona, T. Gabor, and H. Vermeùan, "The analysis of factors that influence the sound absorption coefficient of porous materials," Polyurethane, vol. 40, pp. 105-108, 2014.

[47] M. Ibrahim and R. Melik, "Physical parameters affecting acoustic absorption characteristics of fibrous materials," in Proceedings of the Mathematical and Physical Society of Egypt, p. 46, 1978.

[48] M. Coates and M. Kierzkowski, "Acoustic textiles-lighter, thinner and more sound-absorbent," Technical Textiles International, vol. 11, no. 7, pp. 15-18, 2002.

[49] K. U. Ingard, Notes on Sound Absorption Technology, Noise Control Foundation, Poughkeepsie, NY, USA, 1994.

[50] S. Mahzan, A. Zaidi, A. Mujahid, M. I. Ghazali, M. N. Yahya, and M. Ismail, "Investigation on sound absorption of ricehusk reinforced composite," in Proceedings of the Malaysian Technical Universities Conference on Engineering and Technology (MUCEET '09), pp. 19-22, Kuantan, Malaysia, June 2009. 


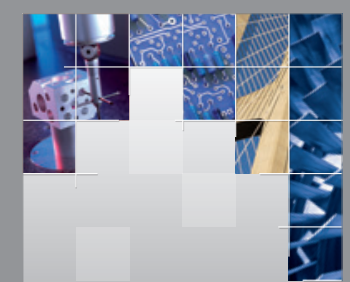

\section{Enfincering}
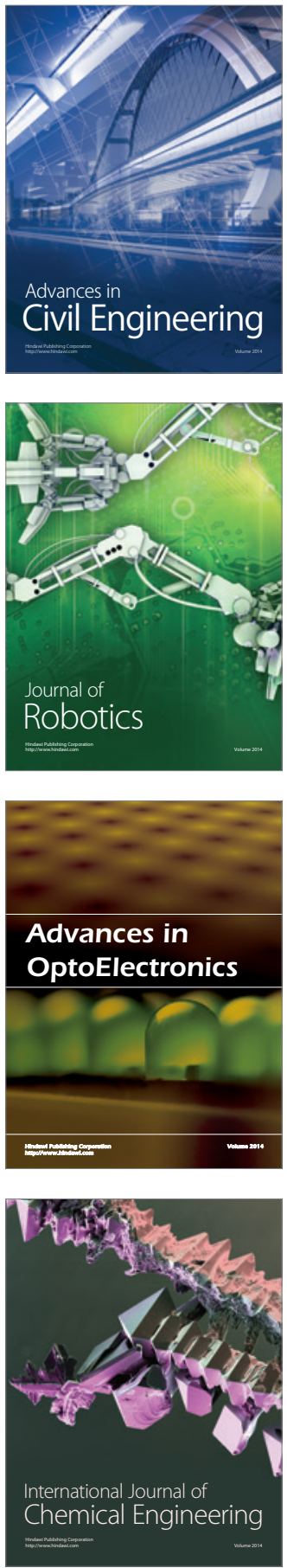

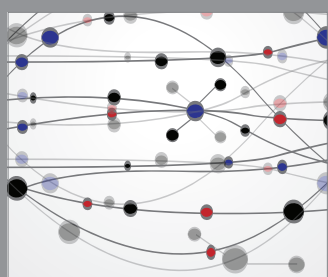

The Scientific World Journal

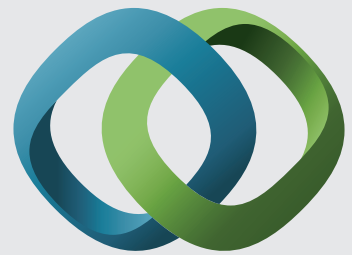

\section{Hindawi}

Submit your manuscripts at

http://www.hindawi.com
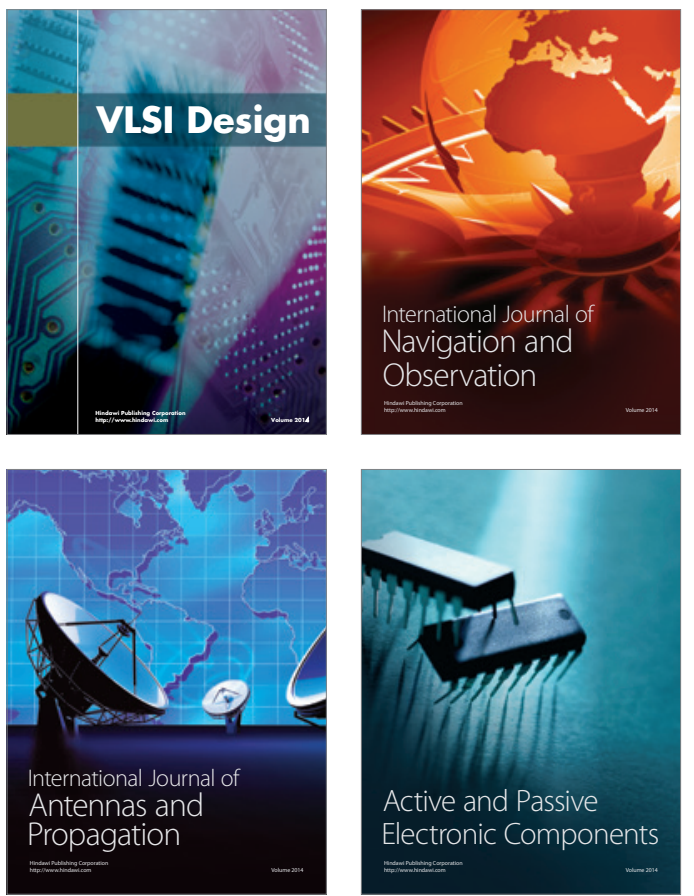
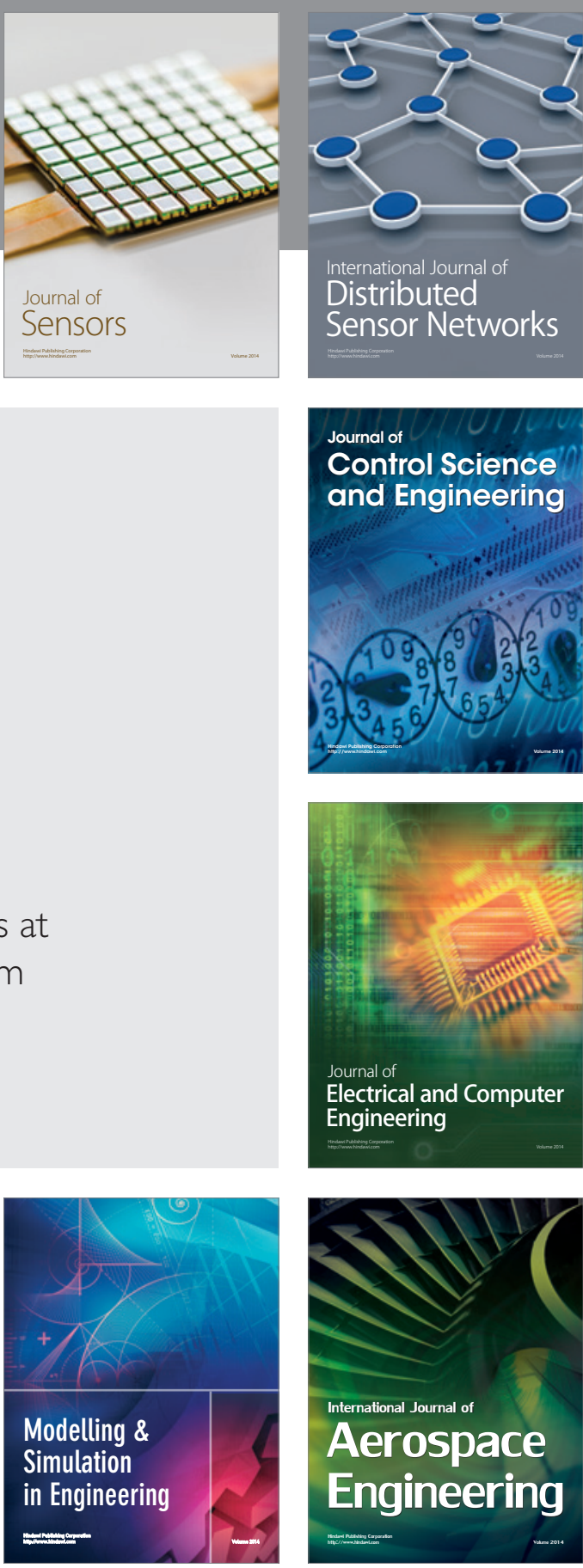

International Journal of

Distributed

Sensor Networks

Journal of

Control Science

and Engineering
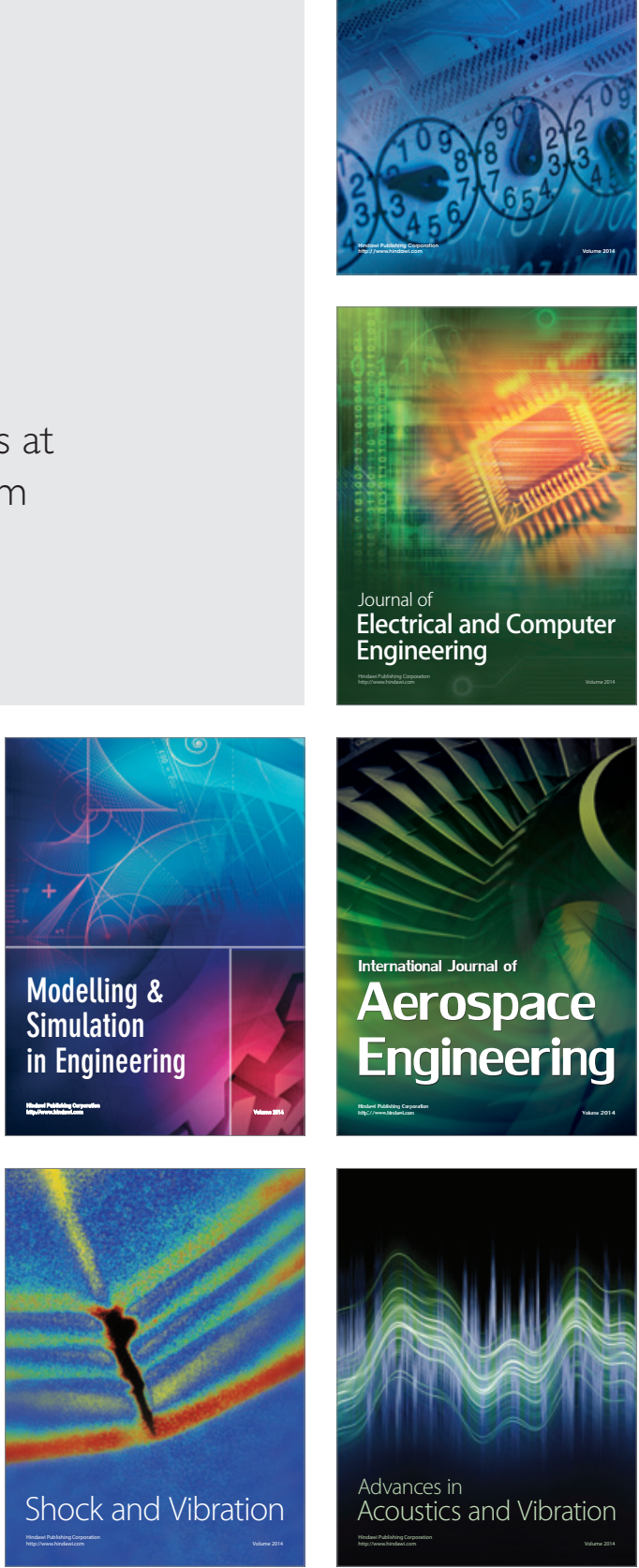